Technical Note

\title{
From GPS Receiver to GNSS Reflectometry Payload Development for the Triton Satellite Mission
}

\author{
Yung-Fu Tsai ${ }^{1, * \mathbb{D}}$, Wen-Hao Yeh ${ }^{1}$, Jyh-Ching Juang ${ }^{2}{ }^{\mathbb{D}}$, Dian-Syuan Yang ${ }^{2}$ and Chen-Tsung Lin ${ }^{1}$ \\ 1 National Space Organization, Hsinchu City 30078, Taiwan; whyeh@narlabs.org.tw (W.-H.Y.); \\ tomlin@narlabs.org.tw (C.-T.L.) \\ 2 Department of Electrical Engineering, National Cheng Kung University, Tainan City 70101, Taiwan; \\ juang@mail.ncku.edu.tw (J.-C.J.); n26084286@gs.ncku.edu.tw (D.-S.Y.) \\ * Correspondence: raymond@narlabs.org.tw
}

Citation: Tsai, Y.-F.; Yeh, W.-H.; Juang, J.-C.; Yang, D.-S.; Lin, C.-T. From GPS Receiver to GNSS Reflectometry Payload Development for the Triton Satellite Mission. Remote Sens. 2021, 13, 999. https:// doi.org/10.3390/rs13050999

Academic Editors: Nereida Rodriguez-Alvarez and Mary Morris

Received: 28 January 2021

Accepted: 27 February 2021

Published: 5 March 2021

Publisher's Note: MDPI stays neutral with regard to jurisdictional claims in published maps and institutional affiliations.

Copyright: (c) 2021 by the authors. Licensee MDPI, Basel, Switzerland. This article is an open access article distributed under the terms and conditions of the Creative Commons Attribution (CC BY) license (https:// creativecommons.org/licenses/by/ $4.0 /)$.

\begin{abstract}
The global positioning system (GPS) receiver has been one of the most important navigation systems for more than two decades. Although the GPS system was originally designed for near-Earth navigation, currently it is widely used in highly dynamic environments (such as low Earth orbit (LEO)). A space-capable GPS receiver (GPSR) is capable of providing timing and navigation information for spacecraft to determine the orbit and synchronize the onboard timing; therefore, it is one of the essential components of modern spacecraft. However, a space-grade GPSR is technology-sensitive and under export control. In order to overcome export control, the National Space Organization (NSPO) in Taiwan completed the development of a self-reliant space-grade GPSR in 2014. The NSPO GPSR, built in-house, has passed its qualification tests and is ready to fly onboard the Triton satellite. In addition to providing navigation, the GPS/global navigation satellite system (GNSS) is facilitated to many remote sensing missions, such as GNSS radio occultation (GNSS-RO) and GNSS reflectometry (GNSS-R). Based on the design of the NSPO GPSR, the NSPO is actively engaged in the development of the Triton program (a GNSS reflectometry mission). In a GNSS-R mission, the reflected signals are processed to form delay Doppler maps (DDMs) so that various properties (including ocean surface roughness, vegetation, soil moisture, and so on) can be retrieved. This paper describes not only the development of the NSPO GPSR but also the design, development, and special features of the Triton's GNSS-R mission. Moreover, in order to verify the NSPO GNSS-R receiver, ground/flight tests are deemed essential. Then, data analyses of the airborne GNSS-R tests are presented in this paper.
\end{abstract}

Keywords: remote sensing; GPS receiver; GNSS reflectometry; DDM; Triton

\section{Introduction}

Due to the omnipresence of global navigation satellite systems (GNSS) signals and their well-maintained infrastructure, many GNSS applications are widely explored. One of most common GNSS space applications is using the direct GNSS signal to provide the position, velocity, and time (PVT) information for orbit determination (Figure 1). The other two space applications are probing the atmospheric and ionospheric profiles with the bending angle and total electron content of the GNSS signal while passing through the atmosphere and ionosphere (GNSS radio occultation, GNSS-RO) and receiving the reflected GNSS signals to sense their surface properties (GNSS reflectometry, GNSS-R). At present, equipping a space-grade global positioning system (GPS) receiver is seen as indispensable for low Earth orbit (LEO) missions because of the convenience of autonomous onboard positioning and timing. The domestic industry in Taiwan (such as MediaTek Inc. and SkyTraq Technology, Inc.) has established a strong capability for designing and manufacturing civil GPS receiver (GPSR) modules/chipsets. However, such a civil GPSR module/chipset is not able to be applied to satellite missions due to the International Traffic in Arms Regulations (ITAR) [1]. In order to overcome export control, the National Space 
Organization (NSPO) has the responsibility to play an important role in promoting the self-reliant technologies of the space industry so that the NSPO has developed the first space-grade GPSR in Taiwan (Figure 2) [2].

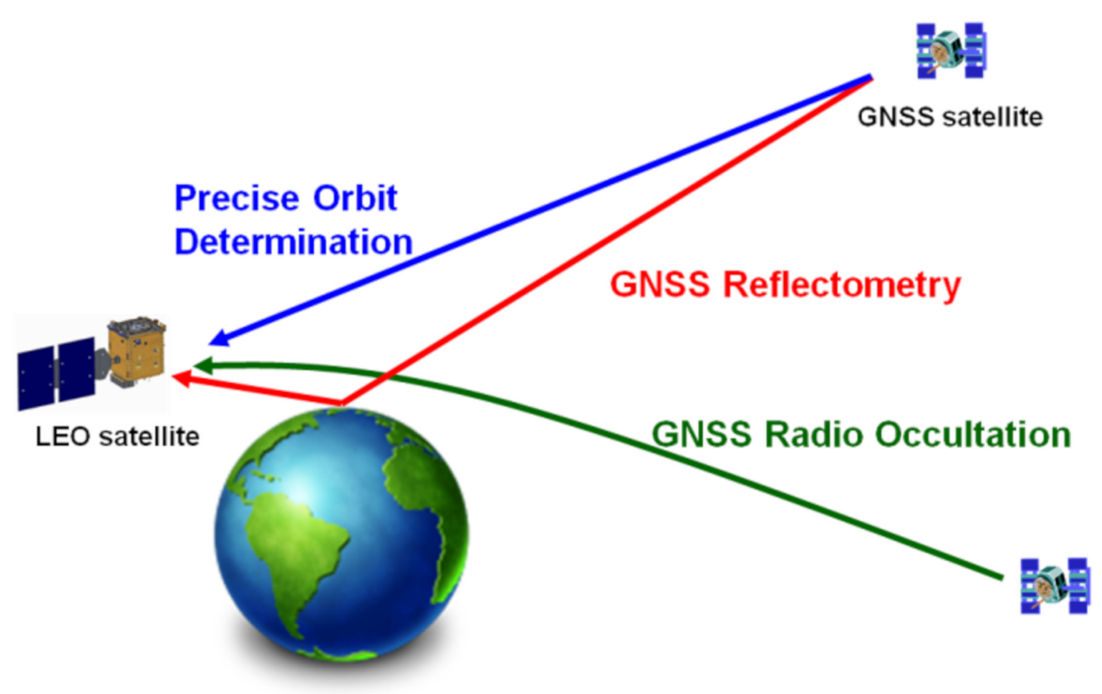

Figure 1. The space applications of global navigation satellite systems (GNSS).

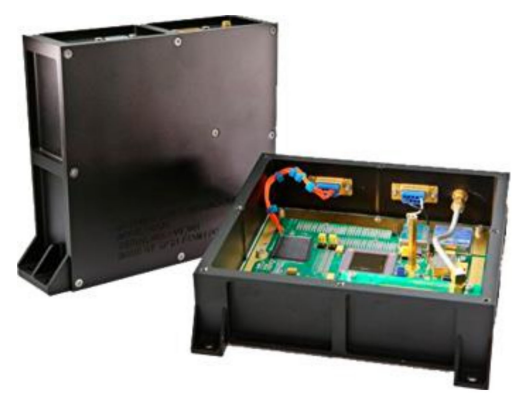

Figure 2. The first space-grade GPS receiver in Taiwan.

The first GPS RO constellation mission is the FORMOSAT-3/COSMIC (simplified as FS-3 in the following descriptions) program, which is an international collaboration program between the NSPO and the University Corporation for Atmospheric Research (UCAR) of the U.S. The FORMOSAT-7/COSMIC-2 (simplified as FS-7) is the follow-up program (launched in 2019) to the successful FS-3 program (which was decommissioned in 2020) and is equipped with the upgraded RO mission payload, which itself is a collaboration between the NSPO and the National Oceanic and Atmospheric Administration (NOAA) of the U.S. Each satellite of the FS-7 constellation is equipped with a GNSS-RO payload to receive the GNSS signal from GPS, GLONASS, and Galileo satellites. The observed $\mathrm{RO}$ data is then downlinked to the ground station to retrieve and process into useful atmospheric and space weather data (such as temperature, pressure, water vapor content, electron density, etc.). The RO data distribution for $24 \mathrm{~h}$ coverage via FS-7 constellation is shown in Figure 3, which includes about 4500 soundings from GPS and GLONASS signals. Currently, the receiving ability of the Galileo signal is under development. Therefore, it greatly increases the amount of atmospheric and ionospheric observation data available at low latitudes, including in Taiwan [3]. In addition to the RO mission, the NSPO is aggressive in the development of new GNSS remote sensing technology so that the GNSS$\mathrm{R}$ mission is selected for the Triton satellite. The main objective of the Triton program is to collect GNSS signals reflected off the Earth's surface from the LEO satellite [4]. The data could be used for research in several remote sensing domains, such as ocean surface wind [5], sea surface height [6], sea ice [7], vegetation [8], and soil moisture [9]. This could 
be especially useful in retrieving wind speed over a sea surface for weather forecasting and typhoon path prediction, thereby benefitting people's livelihoods in Taiwan.

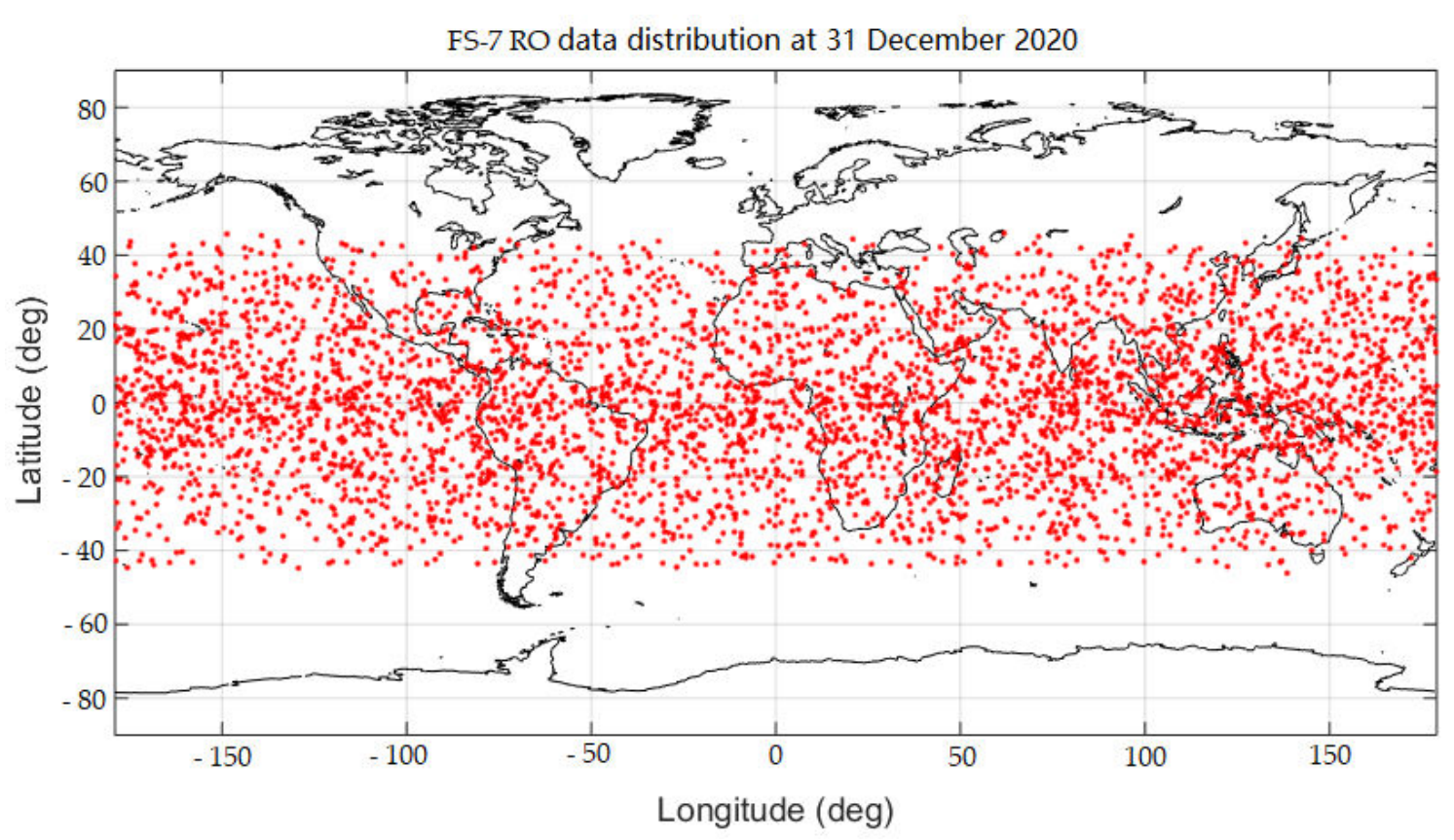

Figure 3. Data distribution for $24 \mathrm{~h}$ coverage by FORMOSAT-7/COSMIC-2 (FS-7) constellation.

\section{Triton Satellite Mission}

The Triton satellite is an experimental micro-satellite designed and manufactured by NSPO and was planned along with the FS-7 program. Hence, in the beginning, it continued to use the FORMOSAT serial number and subjoined a letter " $\mathrm{R}$ " for easier identification (FS-7R). In late 2018, the name "Triton" was officially given due to the GNSS-R mission. In addition to the GNSS-R mission, the Triton satellite mission is conceived as a technology demonstration mission, with the goal of demonstrating some key satellite bus technologies, including the onboard computer (OBC), the power control unit (PCU), $\mathrm{H}_{2} \mathrm{O}_{2}$ propulsion, a fiber optical gyro, a space-grade GPSR, a micro-stepping solar array driving module, and some associated components. These are designed and supplied by domestic industries in order to increase the technology readiness level (TRL) through flight heritage so that a baseline design of a satellite platform with self-reliant components and technologies could be provided for future NSPO missions [10]. However, due to the reduction in the FS-7 program's scope (down from $12+1$ satellites to 6 satellites), the Triton program became less dependent on the FS-7 program, even though the Triton satellite shares some common components with FS-7 satellites, such as a solar array, an S-band transceiver, a reaction wheel, a magnetometer, a coarse sun sensor, magnetic torquers, and a battery. The mass of the Triton satellite is less than $285 \mathrm{~kg}$, and its deployed and stowed configurations are depicted in Figure 4. The dimension of the stowed configuration is approximately $100 \times 120 \times 125 \mathrm{~cm}$. After separation from the launch vehicle, the solar panel will be deployed in space to generate an average power of $162 \mathrm{~W}$.

In this paper, the design and development of the in-house built space-grade NSPO GPSR will be described in the following section, which also includes the performance and environmental tests. This is followed by a presentation of the design, development, and features of the GNSS reflectometry payload. Some unique features of the NSPO self-developed GNSS-R payload will also be highlighted. In order to verify the design of the NSPO's self-developed GNSS-R receiver, several airborne flight experiments have been performed. The data analysis including link budget and data comparison would be 
discussed as well. The conclusion and the updated status of the Triton mission would be presented in the end.

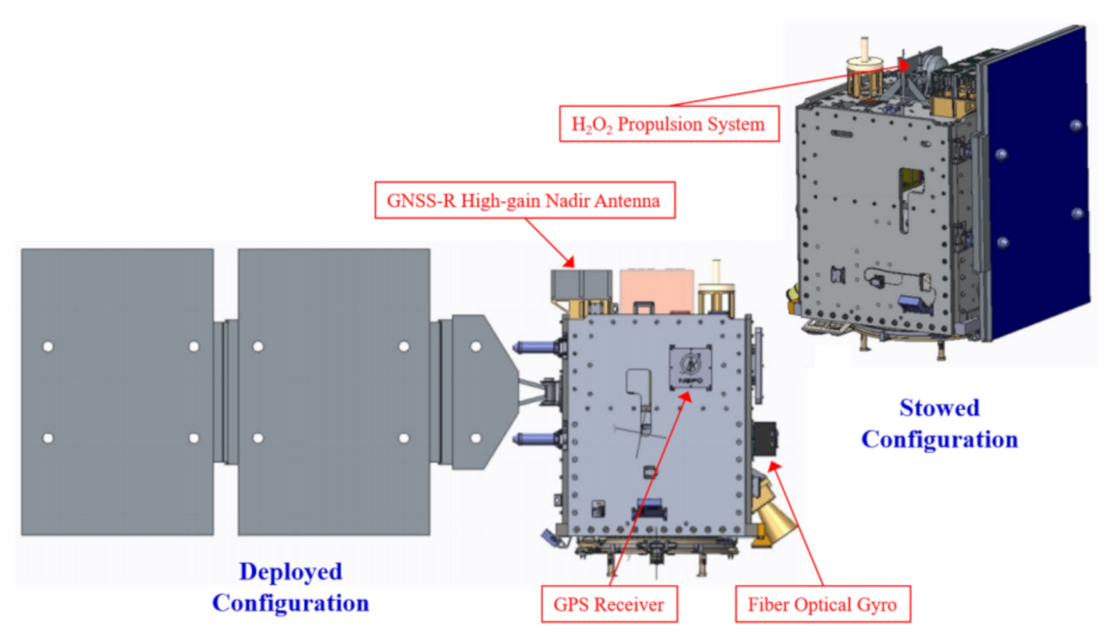

Figure 4. Triton satellite configuration.

\section{GPS Receiver (GPSR) Design/Development}

Figure 5 shows the block diagram of the NSPO GPSR. The MAX2769 IC [11] is the main chip of the radio frequency front-end (RFFE), which is designed for GPS L1 signal conversion and digitalization. The unpacking and filtering of the digitalized RF signal, as well as the interface between the digital signal processor (DSP) and other onboard devices, are implemented into the field programmable gate array (FPGA) unit to reduce the computational load of the DSP. The main processor (the DSP) is in charge of the fast search algorithm engine, signal tracking, almanac/ephemeris decoding, raw measurement forming, navigation solution, orbit propagation, host command and message decoding, and user data exchange.

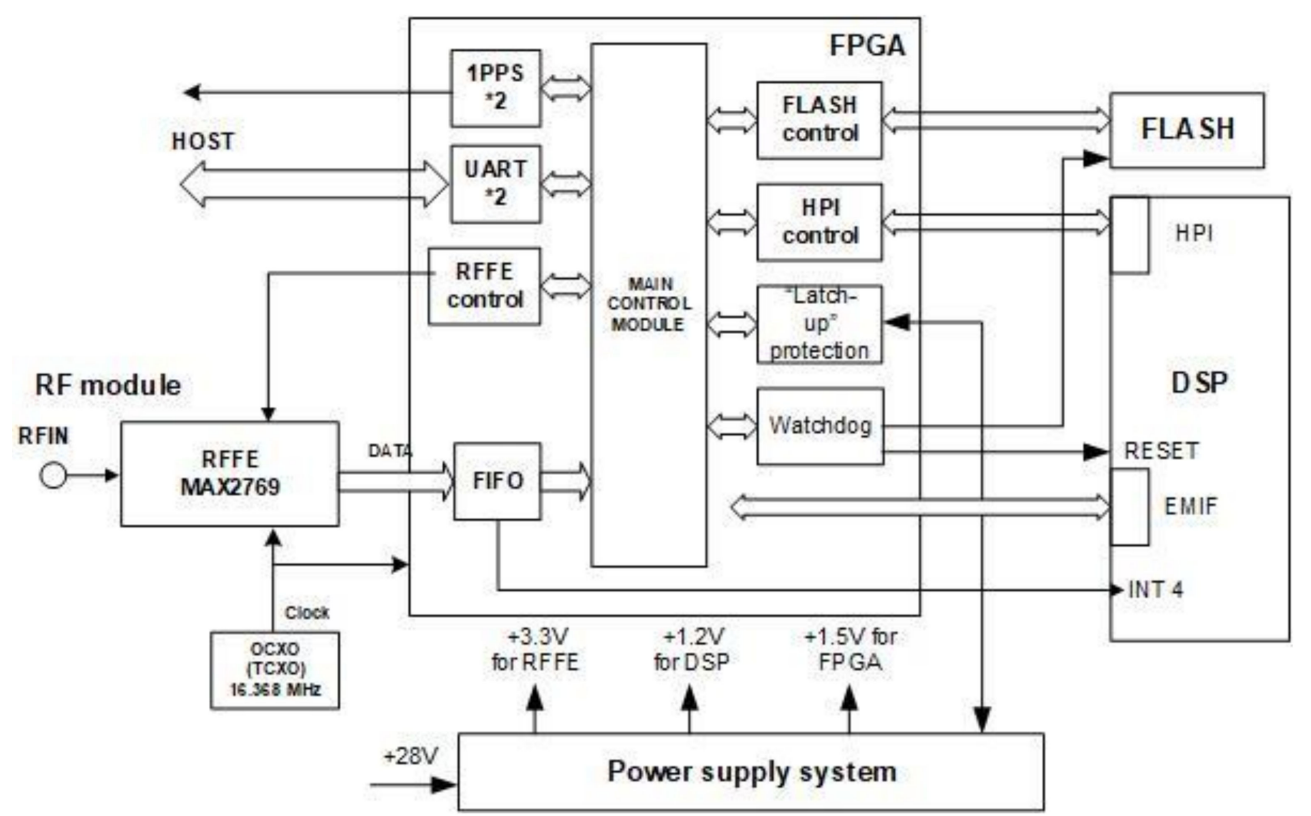

Figure 5. The National Space Organization (NSPO) GPS receiver (GPSR) block diagram.

It is noteworthy that one key feature of the common space-grade GPSRs is its capability to overcome the high Doppler shifts and Doppler shift rates of the high dynamic environment of LEO missions. Figure 6 depicts that the Doppler shift caused by a LEO 
satellite at an altitude of $550 \mathrm{~km}$ is about $\pm 40 \mathrm{kHz}$ and the contact period is only around $40 \mathrm{~min}$. Due to the implementation of the fast search algorithm, the cold start of the NSPO GPSR is within $90 \mathrm{~s}$. It is faster than some of the space-grade GPS receivers, such as the SSTL SGR-07 [12], the New Space NGPS-01-422, and the Astrium MosaicGNSS single-frequency receiver.

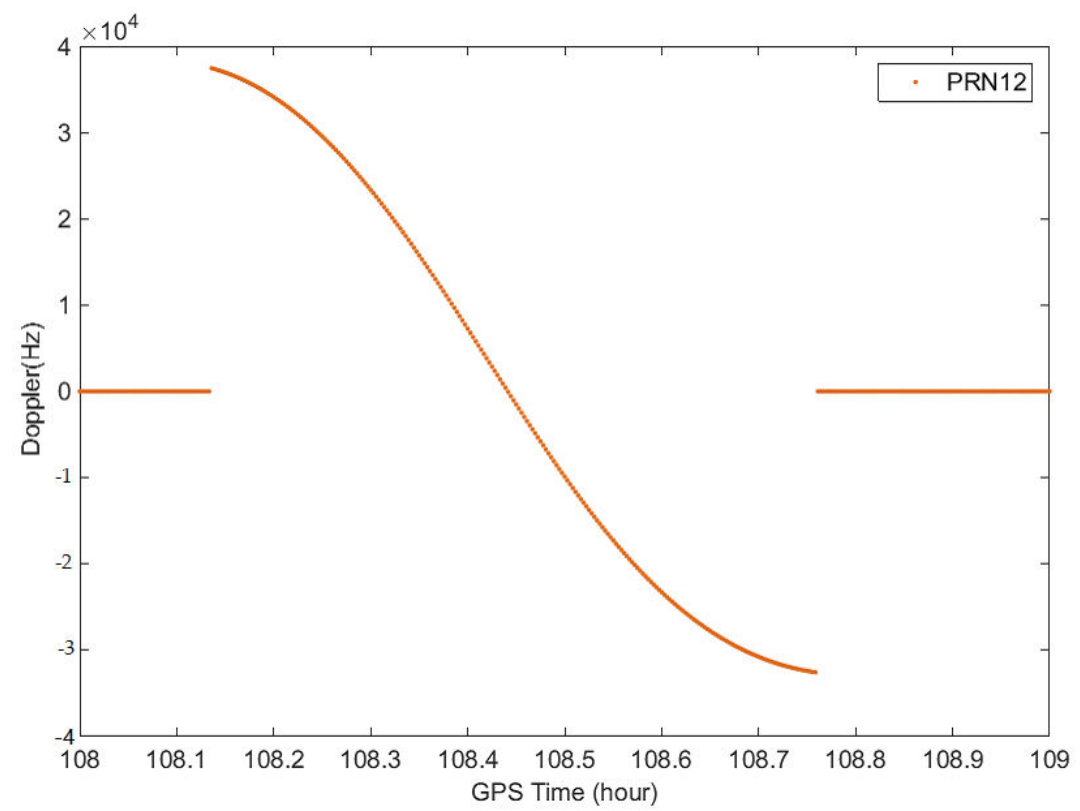

Figure 6. Doppler shift simulation of a low Earth orbit (LEO) mission.

The key specifications of the NSPO GPSR are listed in Table 1. Two types of performance tests have been performed for the NSPO GPSR, with one being a terrestrial test and the other being a high dynamic environment test. In the 4-day terrestrial test, the 3D position and velocity errors of the static GPSR performance are (4.9576, 7.9232, and 5.3995) $(\mathrm{m})$ and $(0.0466,0.0602$, and 0.0396$)(\mathrm{m} / \mathrm{s})$, respectively. In order to verify the capability of the NSPO GPSR, the end-to-end test platform is required to reproduce the RF signal that the receiver will experience in the high dynamic environment. There are two approaches to reproduce the designated GPS signal via Spirent GPS simulator for the high dynamic tests. One is by using pre-loaded motion data files or pre-determined scenarios in the Spirent GPS simulator. The other approach is to construct an attitude control and LEO mission dynamic environment software simulator platform, which is implemented on the NI PXI real time system to generate a corresponding satellite attitude, which is fed into the Spirent GPS simulator in a real time manner [13]. The first high dynamic test was conducted with a predetermined scenario of the orbit of altitude set at $780 \mathrm{~km}$ and the inclination set at $45 \mathrm{deg}$. The position and velocity errors of the nine orbits navigation performance test were $(1.7637,1.6696$, and 1.30$)(\mathrm{m})$ and $(0.0283,0.0277$, and 0.0239$)(\mathrm{m} / \mathrm{s})$, respectively. The average time to first fix (TTFF) of the NSPO GPSR cold start for 30 times with the same high dynamic scenario was about $66 \mathrm{~s}$. The other high dynamic test was conducted with the satellite attitude at a rate of $1 \mathrm{deg} / \mathrm{sec}$ to validate the NSPO GPSR's tracking stability during satellite tumbling. The upper two sub-figures of Figure 7 show the position and velocity error, respectively. The third sub-figure depicts the number of tracked GPS signals (blue line) and the number of tracked GPS signals used for navigation (red line). The lowest sub-figure indicates the information concerning the attitude of the LEO satellite, which means that the satellite is tumbling. Hence, the NSPO GPSR maintains the navigation solution (after $150 \mathrm{~s}$ ), even if the satellite is in a tumbling situation [14]. In addition to the performance test, the environmental tests are essential to verify that the NSPO GPSR is compliant with its specification and is ready to fly with LEO missions. The NSPO GPSR has passed the entire qualification test campaign, undergoing such tests as a thermal cycle 
test, a vibration test, a thermal vacuum test, an electromagnetic compatibility (EMC) test, and a radiation test [15].

Table 1. The specifications of the NSPO GPSR.

\begin{tabular}{cc}
\hline Input power & \multicolumn{1}{c}{$28 \mathrm{~V} / 3.5 \mathrm{~W}$} \\
\hline Electrical interface & RS422/UART@115200 bps \& 1 PPS output \\
\hline Tracking channels & $33 \mathrm{~dB}-\mathrm{Hz}$ \\
\hline Tracking threshold & $\pm 65 \mathrm{KHz}$. \\
\hline Max Doppler shift & Better than $8 \mathrm{~m}(1$ sigma $)$ \\
\hline Position accuracy & Better than $0.1 \mathrm{~m} / \mathrm{s}(1$ sigma $)$ \\
\hline Velocity accuracy & Better than $1 \mathrm{micro}-$ second \\
\hline Time accuracy & Within $90 \mathrm{~s}$ \\
\hline Cold start time & $\mathrm{Up}$ to $12 \mathrm{~g}$ \\
\hline Trajectory dynamic & $1.8 \mathrm{~kg}$ \\
\hline Mass & $160 \times 120 \times 40 \mathrm{~mm}$ \\
\hline Dimension & 5 years \\
\hline Mission life & $35 \mathrm{Krad}$ \\
\hline Total doze &
\end{tabular}

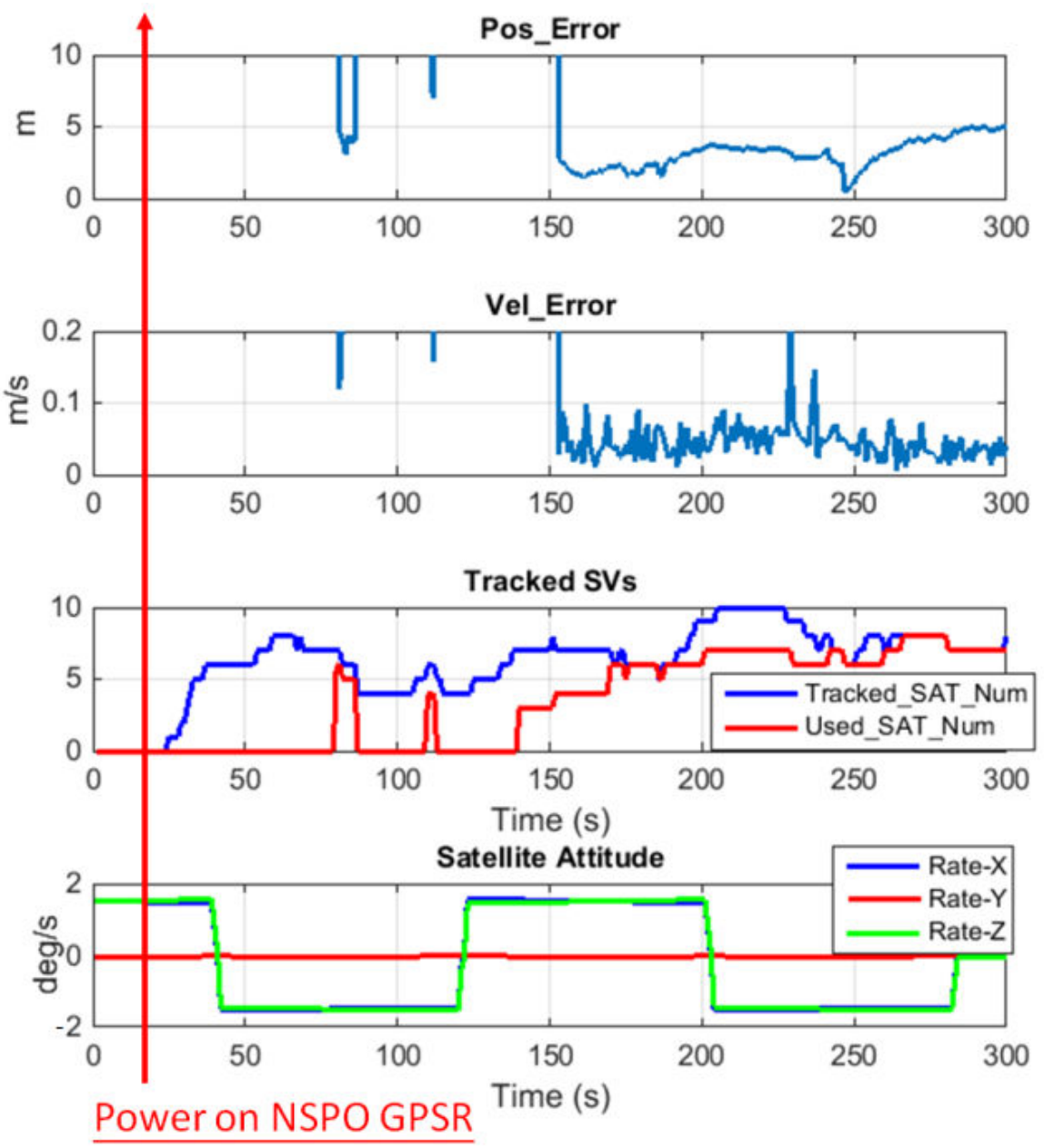

Figure 7. The tracking stability of the NSPO GPSR. 


\section{GNSS Reflectometry (GNSS-R) Mission Payload}

\subsection{GNSS-R Payload Design}

The major task of the GNSS-R receiver is to receive and process reflected GNSS signals, after which the features on the surface of the earth can be retrieved. Therefore, the retrieval of the data concerning wind speed over the ocean is the main objective of the Triton mission. The design of the NSPO GNSS-R payload is based on several applicable GNSS-R processing options, which are discussed in [16]. By examining the needs and referring to the design of the SGR-ReSI (an existing GNSS-R receiver) [17], the GNSS-R payload is designed as a scatterometer, which includes the following requirements [18].

- The GNSS-R payload shall be able to process GPS L1 reflection signals and then generate the associated delay-Doppler map (DDM), either autonomously or by schedule.

- The generated DDM resolution shall be at least 128 (in code phase) * 64 (in frequency bin) and each entry of the DDM shall be better than 16 bits.

- The GNSS-R payload shall be capable of processing at least four DDMs simultaneously.

- The DDM update rate shall be at least $1 \mathrm{~s}$.

- The GNSS-R payload should potentially be extended to process reflected QuasiZenith Satellite System (QZSS) [19] and Galileo L1 signals and generate DDMs of the aforementioned space, magnitude, and time resolution in real time.

- The GNSS-R payload shall be able to record direct line-of-sight and reflected GPS L1/L2 band signals in raw data format at the intermediate frequency (IF) for ground post-processing purposes.

- The GNSS-R payload shall include at least $512 \mathrm{M}$ bytes of RAM to store the raw data.

- $\quad$ The GNSS-R payload shall be designed with a process-and-record mode for ground debugging purpose.

- The GNSS-R payload shall facilitate meta-data to support calibration and retrieval.

The photo of the GNSS-R payload system is depicted in Figure 8. The zenith antenna is a commercial dual-frequency (L1 and L2) right-hand circularly polarized (RHCP) antenna for the reception of the direct line-of-sight signals from GNSS satellites. The nadir antenna is a high-gain dual-frequency left-hand circularly polarized (LHCP) antenna that is used to receive the reflected/scattered signals from GNSS satellites. The low noise amplifier (LNA), installed close to the antenna, is used to provide the appropriate amplification to enhance the signal-to-noise ratio (SNR). Both the nadir antenna and the LNA are designed and supplied by the cooperation of the NSPO and domestic industries. There are a RFFE with two RF inputs, a navigation unit, a science unit, and a power unit inside the GNSS-R receiver. The RFFE is in charge of signal conditioning, down-conversion, and analog-todigital conversion. The incoming signals are sampled at $16.368 \mathrm{M}$ samples per second, and each sample is represented as 4-bit data (2-bit in-phase/ 2-bit quadrature). The core technology of the navigation unit is based on the NSPO GPSR, and it can process the zenith antenna signal to provide PVT information and GNSS satellite position/velocity information. The timing information is used to synchronize the generation of DDM. The PV information and the GNSS satellite PV information are used to compute the specular reflection point. Moreover, the tracking information provided by the navigation unit (such as code phase, code phase rate, and Doppler frequency) is used to determine the relative code shift and Doppler shift for the DDM processing. The telemetry/telecommand (TM/TC) interface of the GNSS-R payload is RS422 in order to operate and monitor the GNSS-R payload. The output data of the science unit (which includes generated DDM and/or stored raw data) are transmitted to the Triton satellite bus through the SpaceWire interface. The transmitted pulse per second (PPS) signal is used for the purpose of synchronization. The power unit regulates the input power from the Triton satellite bus to distribute regulated voltage to the other units. The kernel of the GNSS-R receiver, its science unit, is responsible for the reception and processing of reflected GNSS signals to generate DDMs in real time. The science unit of the GNSS-R receiver is implemented by using a FPGA co-processor (Zynq-7045) to meet the demands of real-time processing. 
Compared with the SGR-ReSI used in the TechDemoSat-1 and CYGNSS missions [20], both reflectometry receiver designs are similar in terms of major functionality. However, there are still some upgraded/distinguishable features of the NSPO GNSS-R payload, which are listed as follows:

- A higher DDM resolution (CYGNSS: one-fourth chip/500 Hz, Triton: one-sixteenth chip/125 Hz)

- A real-time QZSS reflected signal processing capability

- The capability to generate eight DDM generations per second

- On-orbit software/firmware modification capability

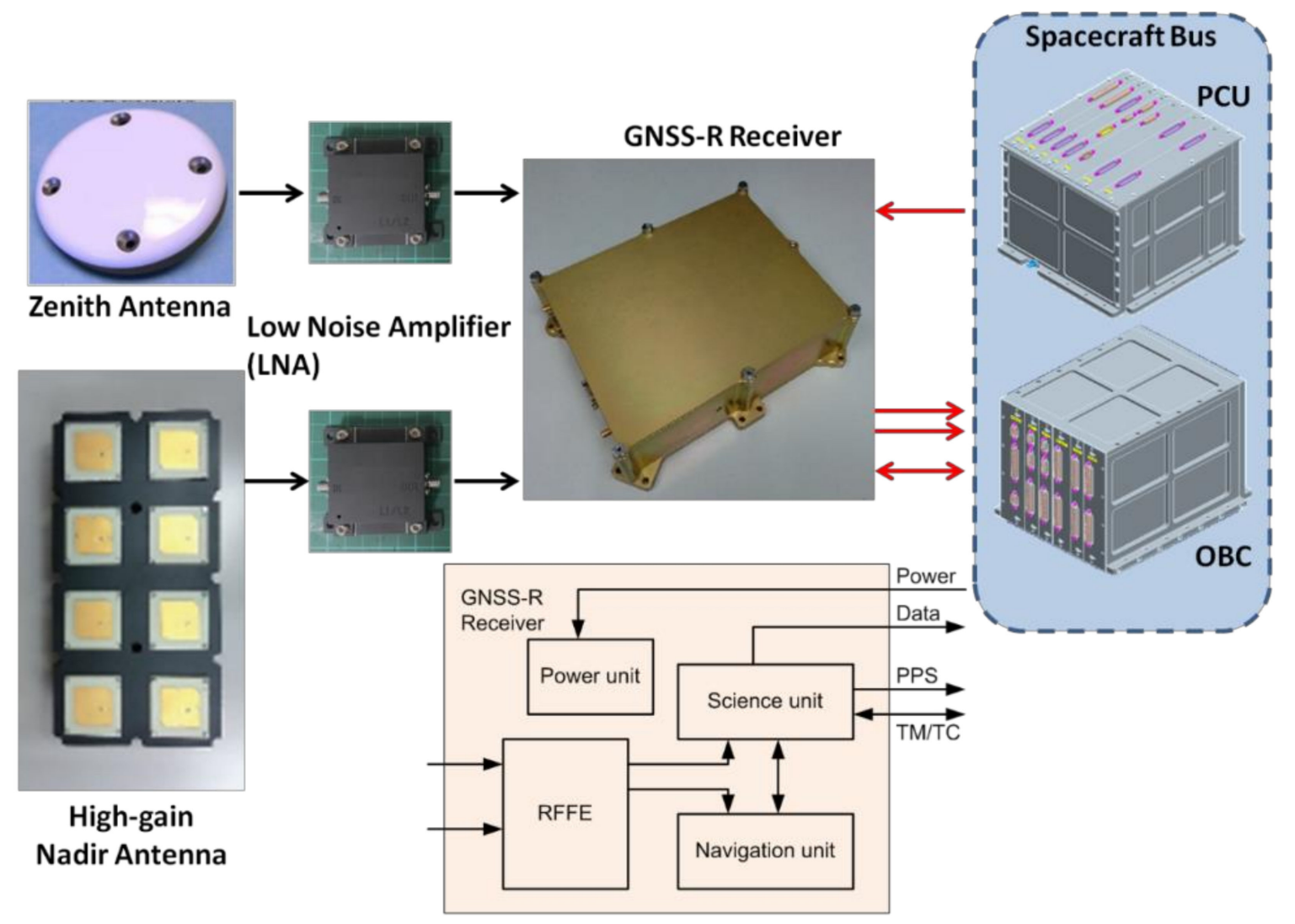

Figure 8. The GNSS-R payload system.

\subsection{GNSS-R Payload Validation}

The prototype of the NSPO self-developed GNSS-R receiver was designed and implemented in 2016. Figure 9 shows the ground test configuration of the GNSS-R prototype, and the test location is on the bridge over the river mouth. There is a dual-frequency zenith antenna to receive the direct line-of-sight GNSS signals, and the nadir antenna (an LHCP $2 \times 2$ pitch antenna) is set up to point to the surface of the river mouth to collect the reflected GNSS signals and generate the corresponding DDMs. Although several ground tests have been conducted to validate the prototype of the GNSS-R payload in the early development phase, two airborne tests have been performed with an Aerospace Industrial Development Corporation (AIDC) airplane at the end of 2016 to verify the functionality of the GNSS-R receiver [21-25]. Figure 10 depicts one snapshot of the aircraft position and four specular point positions (red points), as well as four corresponding DDMs (PRN6, PRN19, PRN17 and PRN 9), respectively. Each entry of the DDM (the correlation value) is indicated by the color as well as the $\mathrm{x}$-axis and $\mathrm{y}$-axis of the DDM are the Doppler frequency bin and the code delay, respectively. After that, the development processes of the engineering model (EM), the engineering qualification model (EQM), and the flight model (FM) 
were completed in 2017, 2018, and 2019, respectively. The entire qualification/acceptance level environmental tests, including the thermal cycle test, the vibration test, the thermal vacuum test, and the electromagnetic compatibility (EMC) test, have been performed and passed as well.

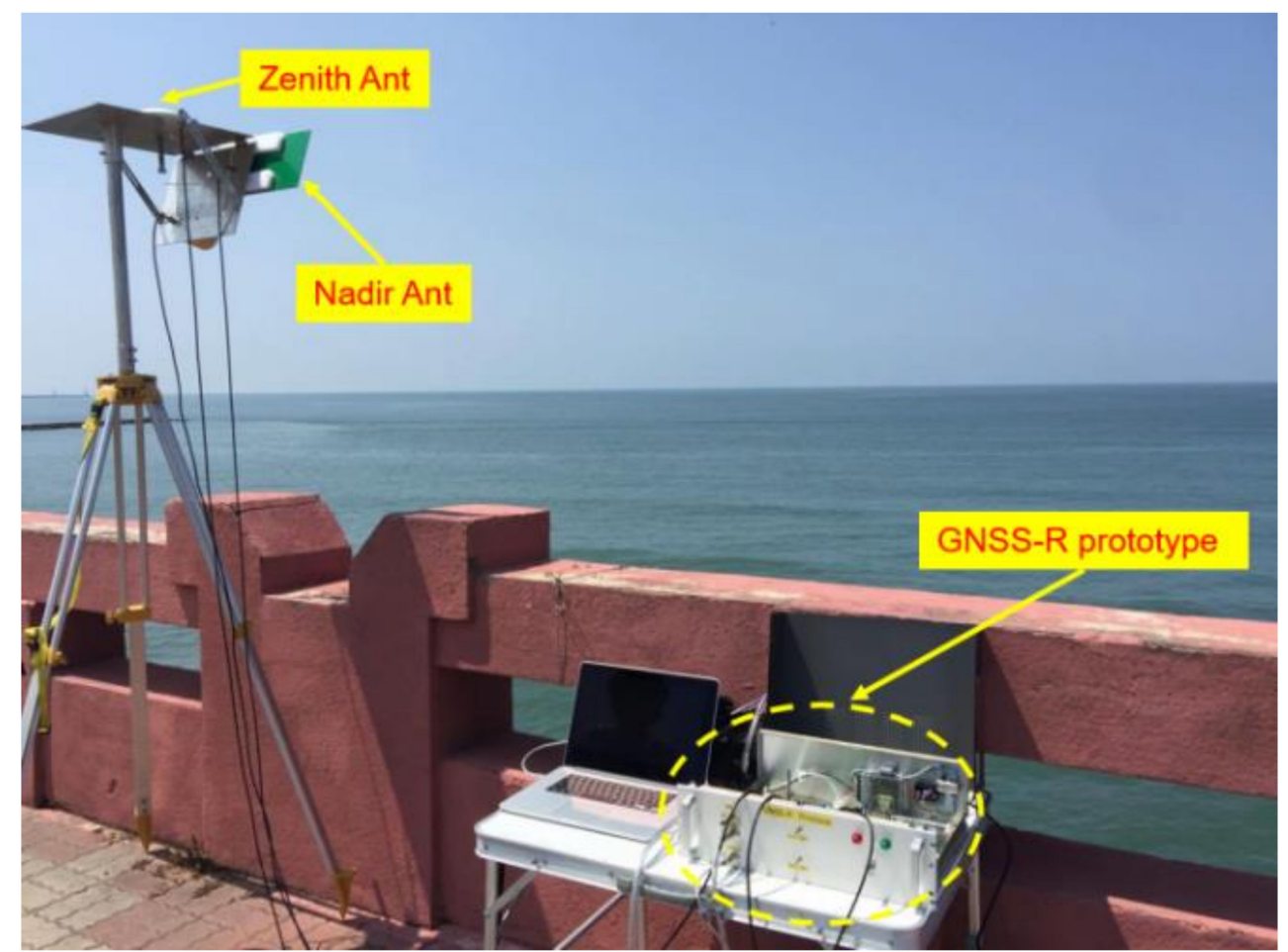

Figure 9. Ground test with the GNSS-R prototype.
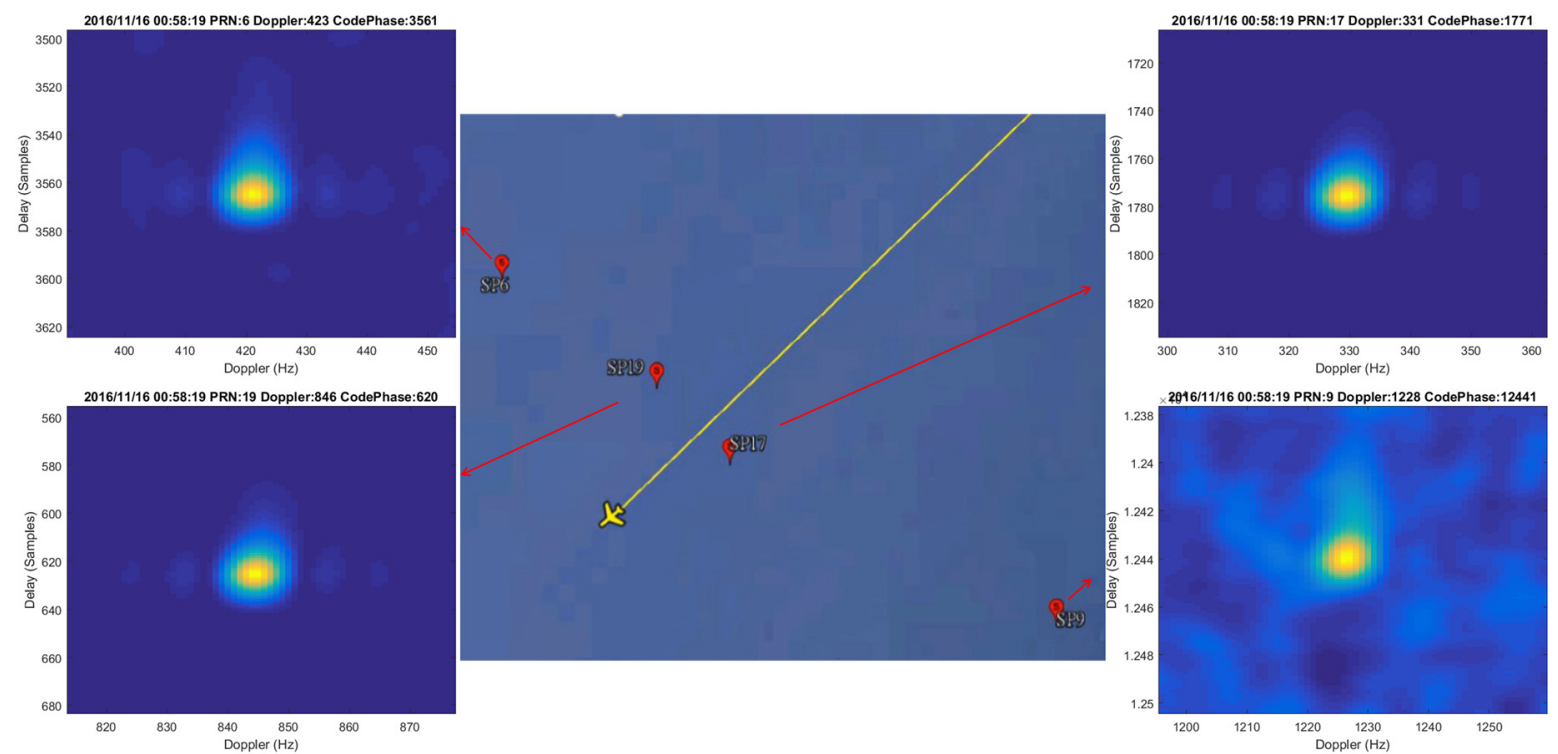

Figure 10. One snapshot of the aircraft position, four specular point positions (red points) and four corresponding DDMs.

Owing to the flexibility of unmanned aerial vehicle (UAV) flight tests, several UAV flight tests with GNSS-R EM were performed during the EQM/FM development phase. The configuration of the UAV flight tests is depicted in Figure 11. Figure 12 shows one snapshot of the four DDMs, the corresponding specular point positions (red circle points), and the UAV flight path. Moreover, it is shown that the interference of the UAV engine 
is introduced into the DDMs. Hence, the objectives of the UAV flight tests were to verify the functionality, operation scheduling, status monitoring, and data science data volume validation of the NSPO GNSS-R receiver. Because there was no interference issue in the 2016 AIDC flight tests, the AIDC airplane was used to carry the GNSS-R EM to conduct the reflectometry experiments (Figure 13) in order to assess the data quality generated from the NSPO GNSS-R receiver. Three airborne reflectometry experiments were conducted on $2020 / 07 / 27,2020 / 09 / 03$, and 2020/11/03, respectively. In addition to the DDMs, the data collection of each reflectometry experiment includes the raw data for further post-processing.

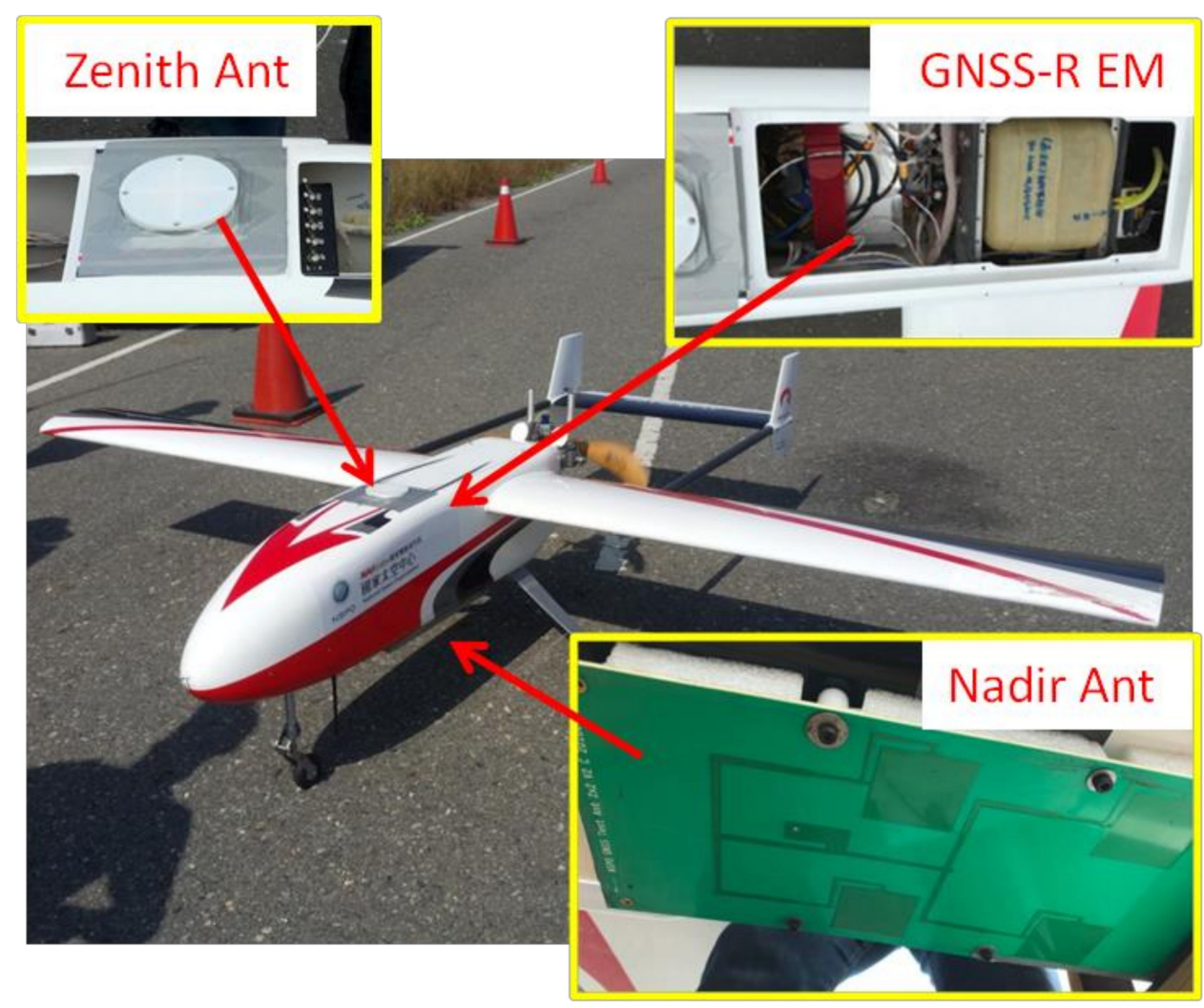

Figure 11. A unmanned aerial vehicle (UAV) flight test with GNSS-R EM.

Figure 14 shows the actual flight path of the AIDC flight test on 27 July 2020. In this figure, the black line is the flight path of the AIDC airplane. In order to avoid the influence of the signal incidence angle and the different transmission power of different GPS satellites, the reflected signal of the QZSS satellite (PRN195) in the flight test is used for analysis. The colored line in Figure 14 is the specular point distribution of PRN195, and the color bar indicates the received power of the reflected signal from the area near the specular point, which is the maximum value of the DDMs (maxDDM). The significant wave height (Hs) observation from the buoy is used for comparison with the received power of the reflected signal. In this experiment, the Hs observations of two buoys (Chimei $\left(22^{\circ} 57^{\prime} 09^{\prime \prime} \mathrm{N} 119^{\circ} 31^{\prime} 06^{\prime \prime} \mathrm{E}\right)$ and Pratas $\left(21^{\circ} 04^{\prime} 39^{\prime \prime} \mathrm{N} 118^{\circ} 50^{\prime} 50^{\prime \prime} \mathrm{E}\right)$ ) were used. These buoys belong to the Center Weather Bureau (CWB), Taiwan. Moreover, a Drifter Technology Co., Ltd. buoy [26] was anchored at $\left(22^{\circ} 55^{\prime} 29^{\prime \prime} \mathrm{N} 119^{\circ} 52^{\prime} 10^{\prime \prime} \mathrm{E}\right)$ to obtain more Hs observations. The diamond, triangle, and square in Figure 14 indicate the buoy positions of the Chimei, Pratas, and Drifter Technology's buoy, respectively. The comparison between Hs and maxDDM is shown in Figure 15 and the symbol indicators of the three buoys are the same as those in Figure 14. The maxDDM information comes from the DDM where the specular point (indicated with the asterisk symbol in Figure 14) is closest to the buoy position, and the red line is the linear regression result. The correlation coefficient between Hs and 
maxDDM is close to -0.99 . According to the result, it is a well negative relation between Hs and maxDDM. This means that the maxDDM decreases as Hs increases, and a higher Hs indicates higher ocean surface roughness. When a signal is reflected by a higher roughness ocean surface, more signal power is scattered and the signal power received is lowered. Hence, it is shown that the quality of the data of the GNSS-R EM is satisfactory.

(a)

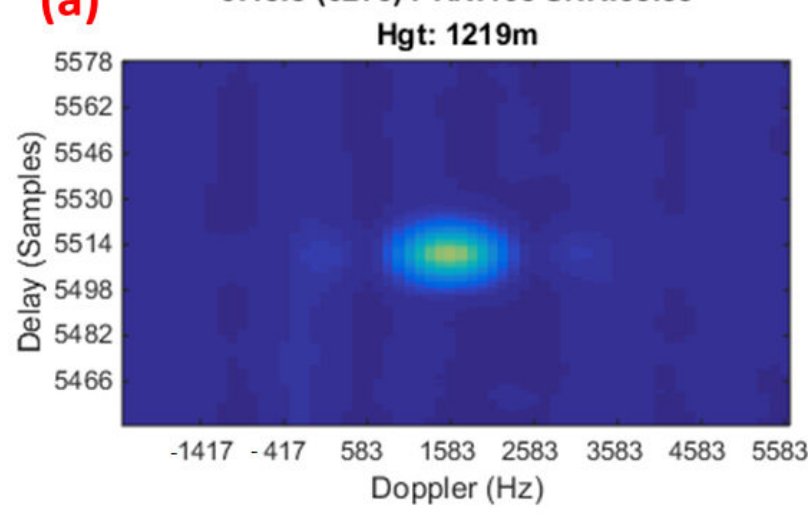

6:18:8 (6275) PRN:17 SNR:26.75

Hgt: $1219 m$

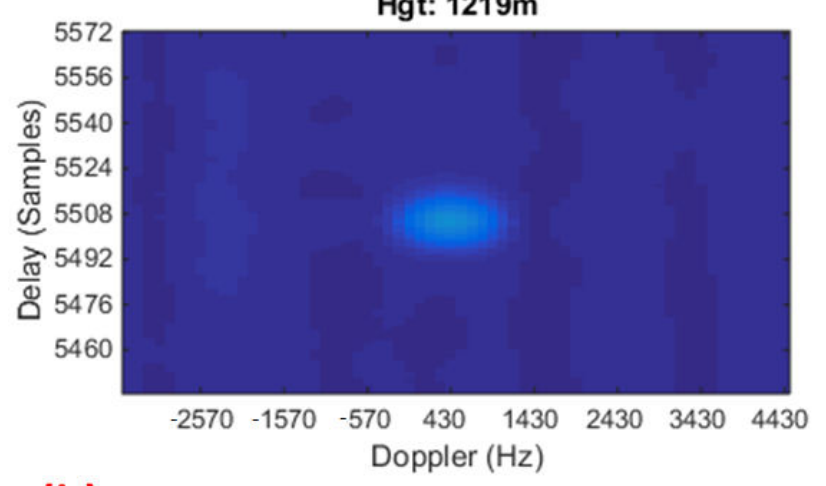

(b)

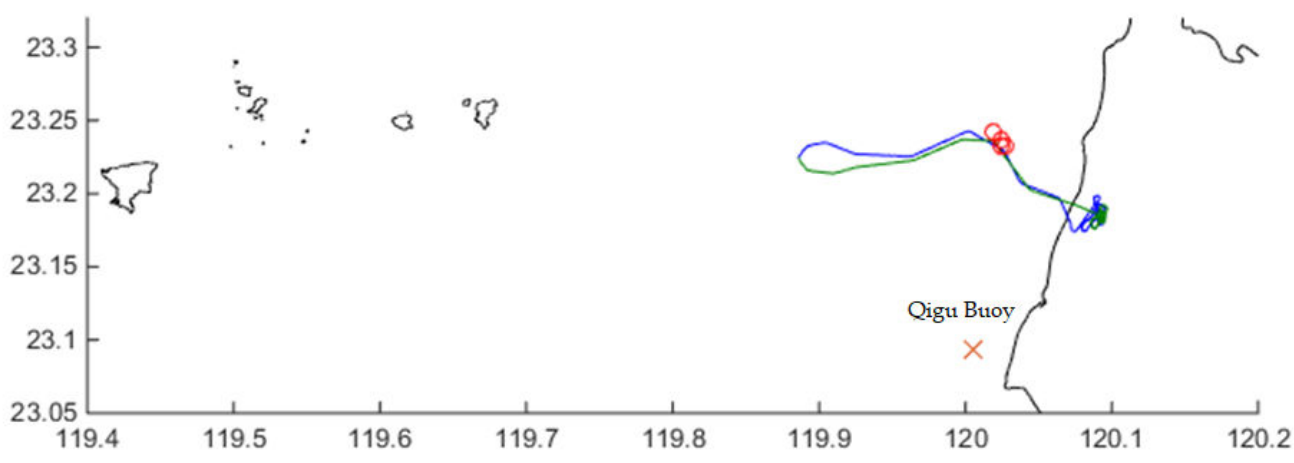

Figure 12. (a) One snapshot of the four DDMs (b) Four corresponding specular point positions (red circle points) at the UAV flight path.
6:18:8 (6274) PRN:19 SNR:38.97

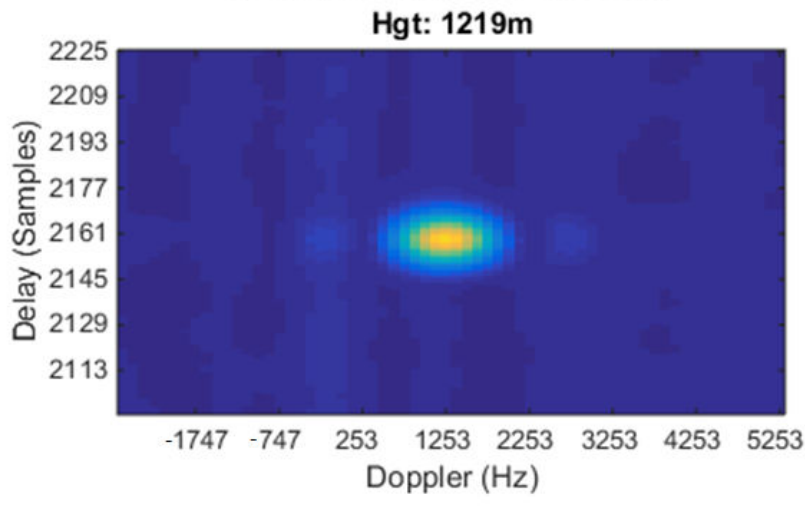

6:18:8 (6276) PRN:6 SNR:22.72

Hgt: $1219 m$

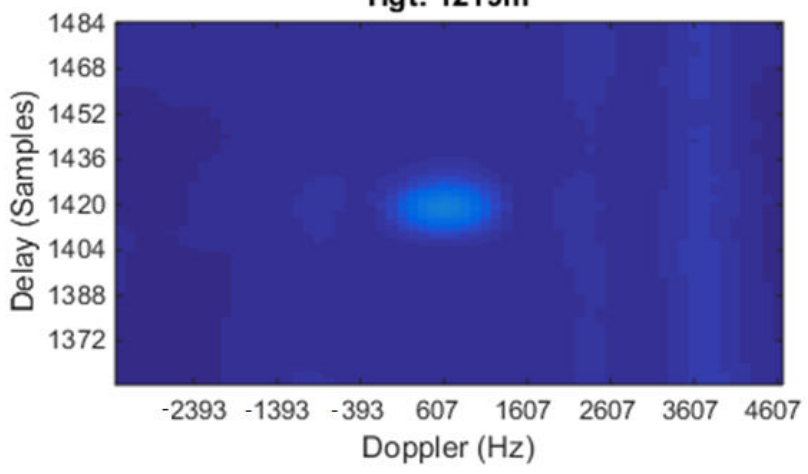




\section{A: GNSS-R EM, a Laptop \& a Power Supply on AIDC Console.}

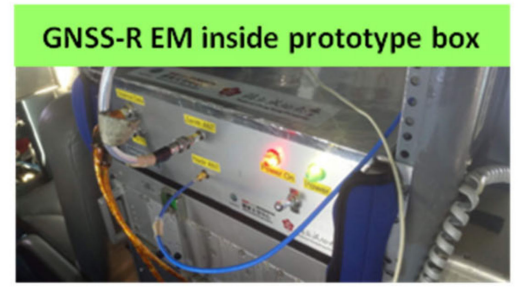

\section{C: A Zenith Antenna \& RF Cable ready for DOTSTAR Program.}

\section{B: A Nadir Antenna mounted underneath a modified RTT-9 Tow Target.}
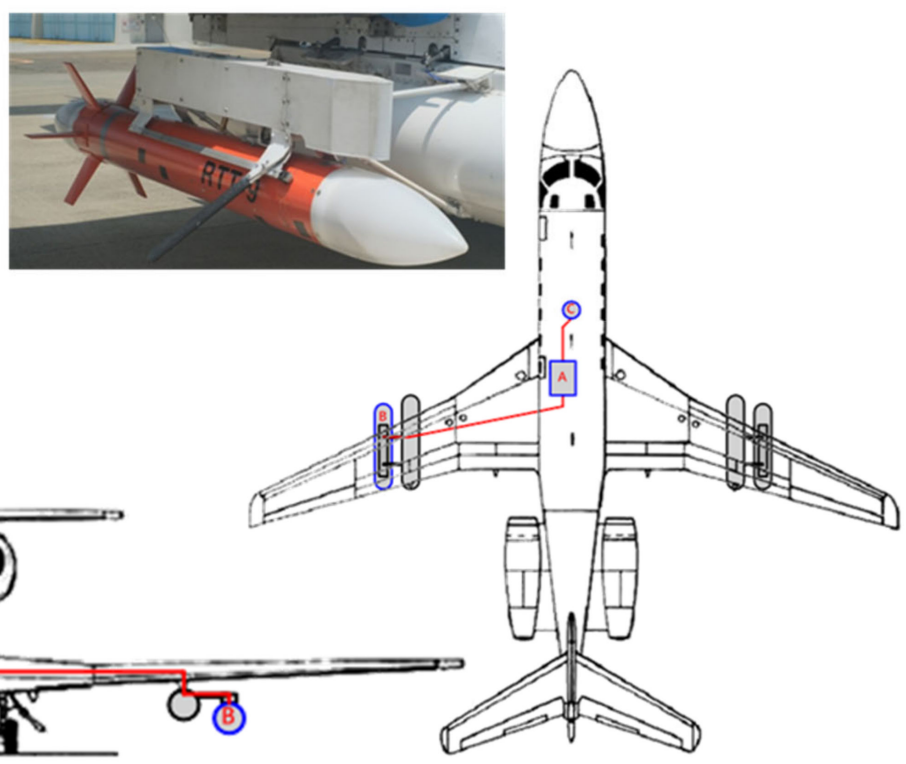

Figure 13. An Aerospace Industrial Development Corporation (AIDC) flight test with GNSS-R EM.

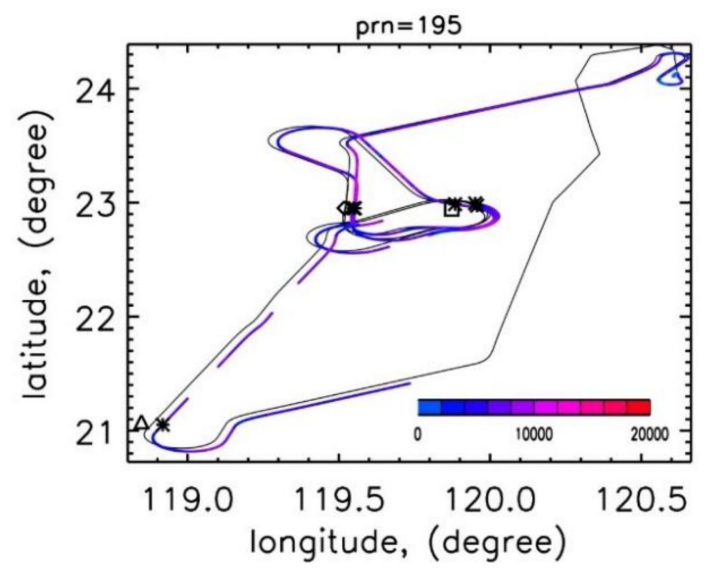

Figure 14. The actual flight path of AIDC reflectometry experiment conducted on 27 July 2020.

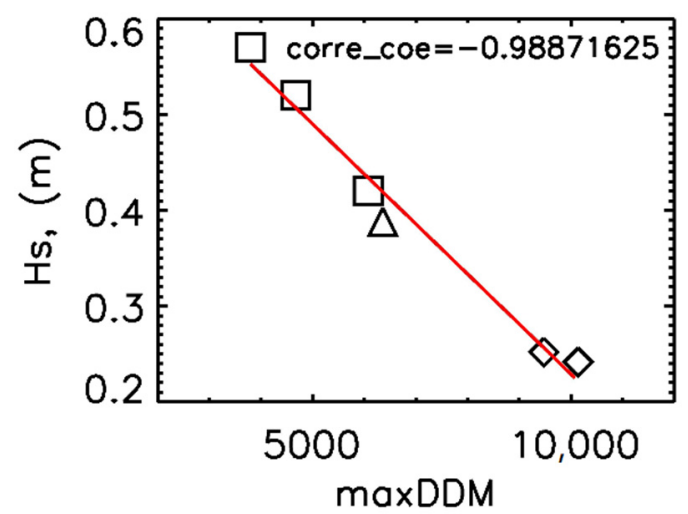

Figure 15. Comparison between the Hs of a buoy and maxDDM (Chimei, Pratas, and Drifter Technology's buoy are indicated with the diamond, triangle, and square).

Moreover, since the scattered/reflected GNSS signals for space application are extremely weak, a link budget analysis is performed and compared with real collected DDM 
SNR (defined in Figure 16) to validate the design parameters, including antenna gain and coherent/non-coherent processing parameters. The theoretical model DDM could be represented by the following GPS bi-static radar equation:

$$
\left\langle\left|Y_{S}(\tau, f)\right|^{2}\right\rangle=\frac{P_{T} \lambda_{L 1}^{2}}{(4 \pi)^{3}} \mathrm{~T} i^{2} \iint \frac{G_{T}(\theta, \phi) G_{R}(\theta, \phi) \sigma^{0}(\theta, \phi)}{R_{S R}^{2}(\theta, \phi) R_{S T}^{2}(\theta, \phi)} \Omega(\tau, f, \theta, \phi) d A(\theta, \phi)
$$

where the detailed parameters in the equation are defined in [27]. Therefore, Figure 17 shows the flow chart of the theoretical model SNR calculation for link budget analysis [28]. In the upper part of Figure 17, the input parameters, the GNSS satellite position, and the GNSS-R receiver position are provided by the GNSS-R EM in order to calculate the reflection point. Then, some geo-physical parameters, such as wind speed and GPS equivalent isotropically radiated power (EIRP), are assumed to be at a reasonable value according to CWB broadcast wind speed and the GNSS interface control document (ICD). Moreover, some supplemental information (such as AIDC airplane/UAV attitude, antenna gain pattern, and LAN gain/noise figure look-up table) is provided to calculate the received power and thermal noise over each grid. Finally, each grid is accumulated and processed in a non-coherent integration to obtain the theoretical model DDM SNR. The comparison of 2020/09/03 airborne reflectometry experiment is illustrated in Figure 18. The trending and value are similar so that good confidence is provided for the signal reception of the Triton GNSS-R mission based on the link budget analysis method. However, the average error of the comparison is about $0.5 \mathrm{~dB}$. The reason for this is that some uncertain parameters are difficult to obtain for link budget analysis (for example, real wind speed, GNSS-R receiver/LNA temperatures, etc.).

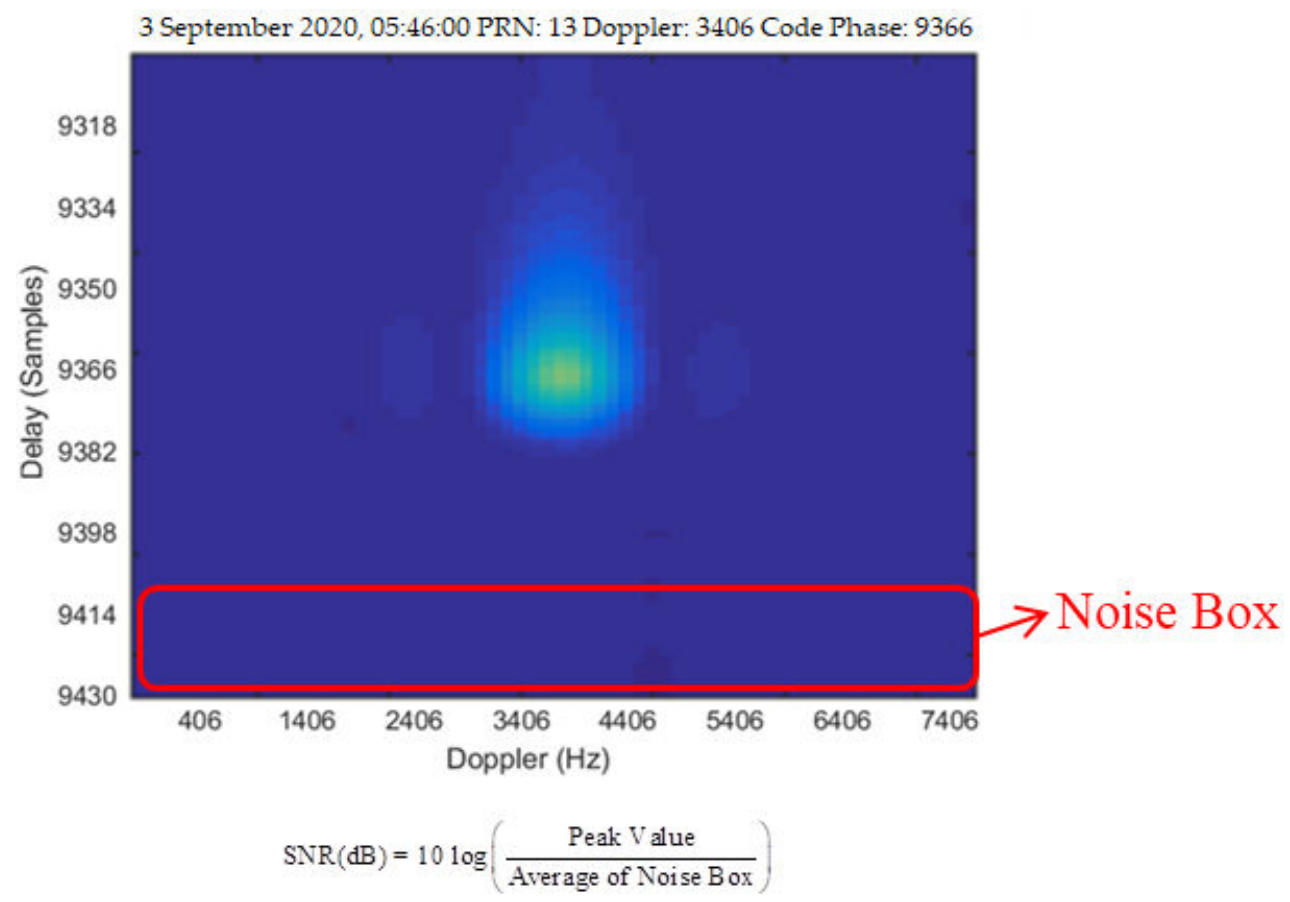

Figure 16. A signal-to-noise ratio (SNR) calculation of DDM. 
(a)
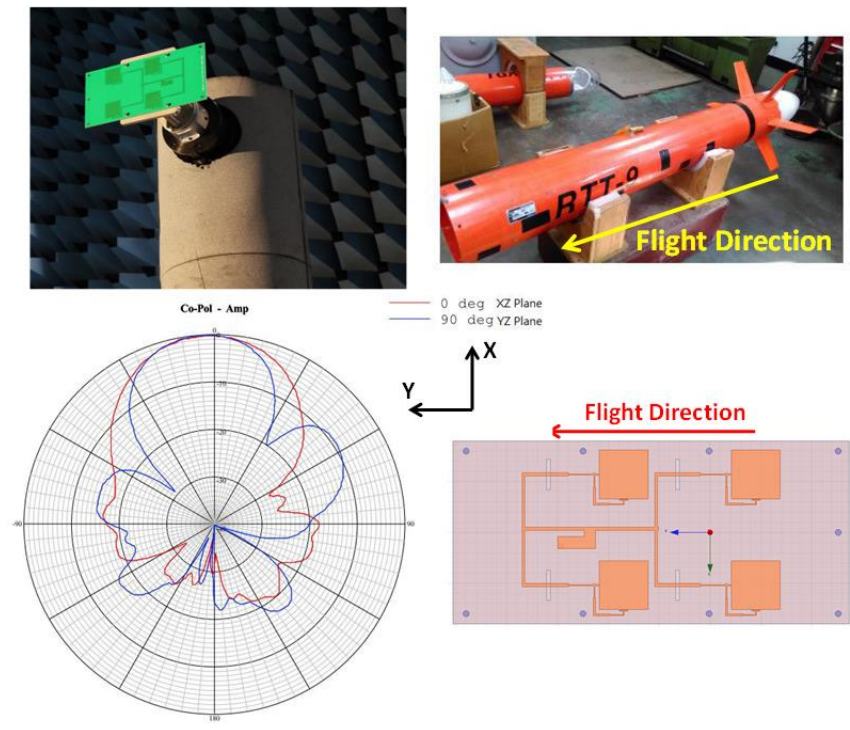

(b)

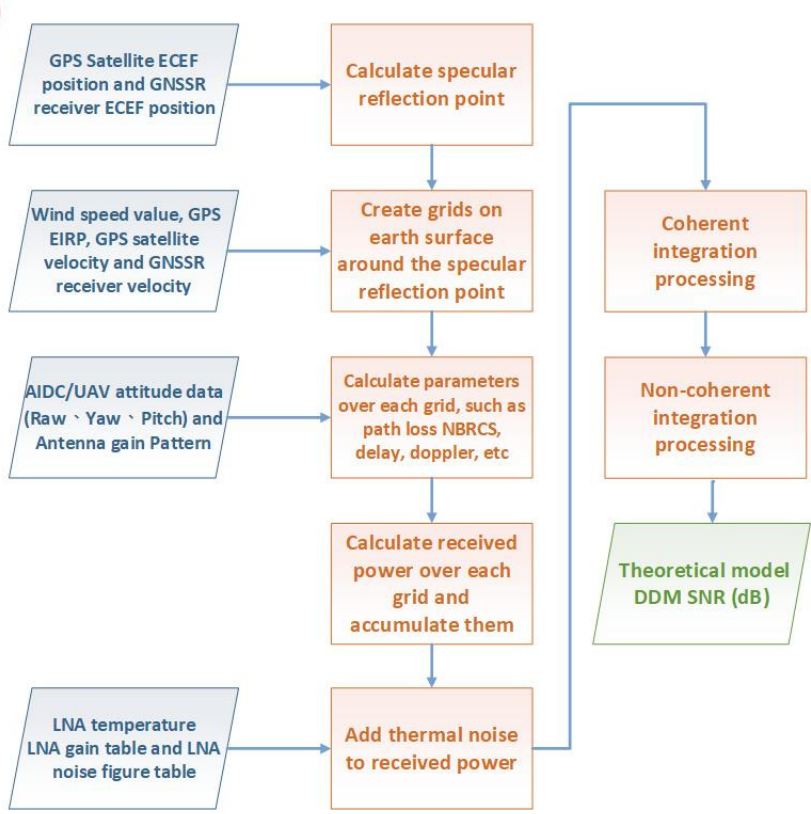

Figure 17. (a) Antenna gain pattern and setup configuration (b) Link budget analysis flowchart.

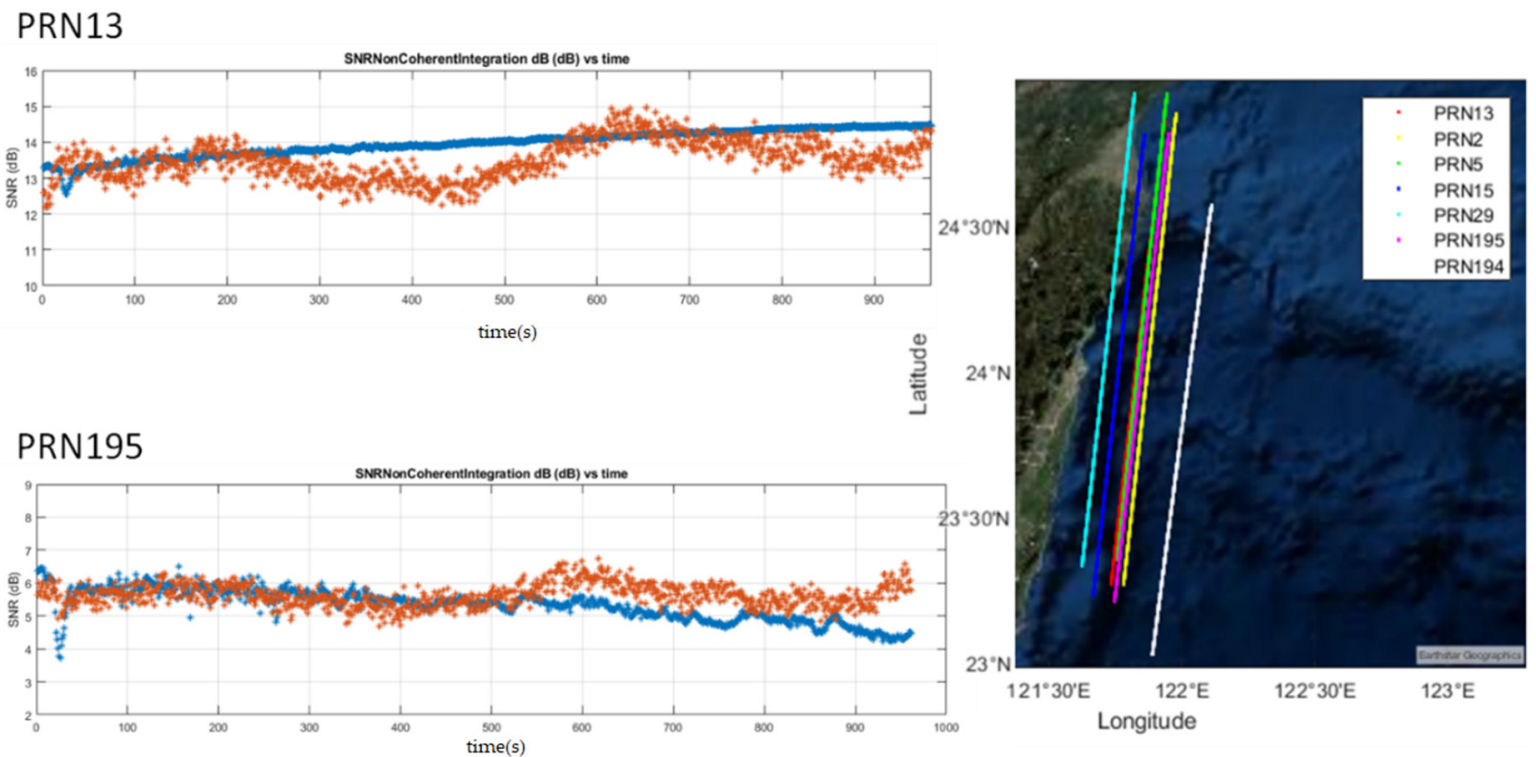

Figure 18. Comparison of the theoretical model (blue) and real collected (red) DDM SNR.

\section{Conclusions}

The introduction of the Triton mission is described at the beginning of the paper. The development of the NSPO GPSR, which is ready to fly onboard the Triton satellite, is then illustrated. Moreover, in order to satisfy the requirements of future NSPO missions and university CubeSats, several miniaturized versions of the NSPO in-house built GPSRs were developed without performance degradation [29]. Afterward, the paper presented not only the design and development of the Triton's GNSS-R mission payload but also the flight tests for the validation of the GNSS-R payload. Moreover, a science team has been formed to perform the tasks of data calibration, data archiving, data retrieval, and data utilization to support the Triton mission. The Triton program started in 2012 and passed several milestones, such as a system design review (SDR), a preliminary design review (PDR), a critical design review (CDR), and an integration \& test review (ITR), before 2018. The NSPO team also has completed the installation of most components, harness routing, 
and integration. The entire environmental tests are planned to be conducted in 2021 so that the Triton satellite is ready to launch in 2022.

Author Contributions: Conceptualization, Y.-F.T. and W.-H.Y.; data curation, D.-S.Y.; writingoriginal draft preparation, Y.-F.T.; writing-review and editing, Y.-F.T. and W.-H.Y.; supervision, J.-C.J.; project administration, C.-T.L. All authors have read and agreed to the published version of the manuscript.

Funding: The APC was funded by the National Space Organization, Taiwan.

Acknowledgments: The authors would like to thank Center Weather Bureau (CWB), Taiwan and Drifter Technology Co., Ltd., Taiwan for providing the buoy data used in this paper.

Conflicts of Interest: The authors declare no conflict of interest.

\section{References}

1. Juang, J.C.; Lin, C.F.; Hu, C.M.; Chang, C.C.; Tsai, Y.F.; Lin, C.T. Implementation and Test of a Space-borne GPS Receiver Payload of University Microsatellite. J. Aeronaut. Astronaut. Aviat. 2012, 44, 141-148.

2. News of NSPO, Taiwan. Available online: http:/ / www.nspo.narl.org.tw/en2016/info/news.shtml?id=000527\&hid=ruEdk2nA2B (accessed on 1 March 2021).

3. FORMOSAT-7 Program, NSPO, Taiwan. Available online: https:/ /www.nspo.narl.org.tw /inprogress.php?c=20022301\&ln=en (accessed on 1 March 2021).

4. TRITON Program, NSPO, Taiwan. Available online: https: / www.nspo.narl.org.tw /inprogress.php?c=20030305\&ln=en (accessed on 1 March 2021).

5. Gleason, S.; Hodgart, S.; Sun, Y.; Gommenginger, C.; Mackin, S.; Adjrad, M.; Unwin, M. Detection and processing of bistatically reflected GPS signals from low earth orbit for the purpose of ocean remote sensing. IEEE Trans. Geosci. Remote Sens. 2005, 43, 1229-1241. [CrossRef]

6. Martin-Neira, M.; Caparrini, M.; Font-Rossello, J.; Lannelongue, S.; Vallmitjana, C.S. The PARIS concept: An experimental demonstration of sea surface altimetry using GPS reflected signals. IEEE Trans. Geosci. Remote Sens. 2001, 39, 142-150. [CrossRef]

7. Yan, Q.; Huang, W. Spaceborne GNSS-R sea ice detection using delay-Doppler maps: First results from the UK TechDemoSat-1 mission. IEEE J. Sel. Top. Appl. Earth Obs. Remote Sens. 2016, 9, 4795-4801. [CrossRef]

8. Small, E.E.; Larson, K.M.; Braun, J.J. Sensing vegetation growth with reflected GPS signals. Geophys. Res. Lett. 2010, 37. [CrossRef]

9. Rodriguez-Alvarez, N.; Bosch-Lluis, X.; Camps, A.; Vall-Llossera, M.; Valencia, E.; Marchan-Hernandez, J.F.; Ramos-Perez, I. Soil moisture retrieval using GNSS-R techniques: Experimental results over a bare soil field. IEEE Trans. Geosci. Remote Sens. 2009, 47, 3616-3624. [CrossRef]

10. Tsai, Y.F.; Lin, C.T.; Juang, J.C. Taiwan's GNSS Reflectometry Mission-The FORMOSAT-7 Reflectometry (FS-7R) Mission. J. Aeronaut. Astronaut. Aviat. 2018, 50, 391-404.

11. Datasheet of MAX2769 Universal GPS Receiver. Available online: https://www.maximintegrated.com/en/products/comms/ wireless-rf/MAX2769.html (accessed on 1 March 2021).

12. Datasheet of Space GPS Receiver SGR-07. Available online: https://sstl-qa.azurewebsites.net/getattachment/Media-Hub/ Featured/Navigation/SGR-07-Datasheet-2018-V2-Read-Only.pdf?lang=en-GB (accessed on 1 March 2021).

13. Chang, H.Y.; Chang, H.C.; Lin, C.T. Performance Demonstration of NSPO Space-borne GPS Receiver. In Proceedings of the 26th International Technical Meeting of the Satellite Division of The Institute of Navigation (ION GNSS+ 2013), Manassas, VA, USA, 21-25 September 2013.

14. Chang, H.Y.; Chiang, W.L.; Wu, K.L. A Space-Borne GNSS Receiver for Evaluation of the LEO Navigation Based on Real-Time Platform. In Proceedings of the CEAS Euro GNC Conference, Warsaw, Poland, 25-27 April 2017.

15. Cheng, C.C.; Lin, C.T.; Chen, T.L. TID Testing and SEE Mitigation Approach of a Long Mission Life GPS Receiver Using COTS Parts. In Proceedings of the 6th ESA Workshop on Satellite Navigation Technologies, Noordwijk, The Netherlands, 5-7 December 2012.

16. Zavorotny, V.U.; Gleason, S.; Cardellach, E.; Camps, A. Tutorial on remote sensing using GNSS bistatic radar of opportunity. IEEE Geosci. Remote Sens. Mag. 2014, 2, 8-45. [CrossRef]

17. Unwin, M.; de Vos Van Steenwijk, R.; Da Silva Curiel, A.; Cutter, M.; Abbott, B.; Gommenginger, C.; Mitchell, C.; Gao, S. Remote sensing using GPS signals-The SGR-ReSI instrument. In Proceedings of the 25th Annu. AIAA/USU Conf. Small Satellites, Logan, UT, USA, 8-11 August 2011.

18. Juang, J.C.; Ma, S.H.; Lin, C.T. Study of GNSS-R Techniques for FORMOSAT Mission. IEEE J. Sel. Top. Appl. Earth Obs. Remote Sens. 2016, 9, 4582-4592. [CrossRef]

19. Quasi-Zenith Satellite System (QZSS). Available online: https://qzss.go.jp/en/overview/services/index.html (accessed on 1 March 2021).

20. CYGNSS Mission. Available online: https:// clasp-research.engin.umich.edu/missions/cygnss/ (accessed on 1 March 2021). 
21. Juang, J.C.; Lin, C.T. Recent Development in GNSS-Reflected Signal Processing and Receiver Research in Taiwan. In Proceedings of the COSMIC/IROWG, Estes Park, CO, USA, 21-27 September 2017.

22. Juang, J.C.; Ma, S.H.; Lin, C.T. Data Analysis of Galileo Reflected Signals in an Airborne Experiment. In Proceedings of the GNSS+R, 2017 Workshop, University of Michigan Union, Ann Arbor, MI, USA, 23-25 May 2017.

23. DOTSTAR Project. Available online: http:/ / typhoon.as.ntu.edu.tw/DOTSTAR/en/ (accessed on 1 March 2021).

24. Juang, J.C.; Tsai, Y.F.; Lin, C.T. FORMOSAT-7R Mission for GNSS Reflectometry. In Proceedings of the 2019 IEEE International Geoscience and Remote Sensing Symposium, IGARSS 2019, Yokohama, Japan, 28 July-2 August 2019.

25. Juang, J.C.; Lin, C.T.; Tsai, Y.F. Comparison and Synergy of BPSK and BOC Modulations in GNSS Reflectometry. IEEE J. Sel. Top. Appl. Earth Obs. Remote Sens. 2020. [CrossRef]

26. Drifter Technology Co. Ltd. Available online: http://driftertek.com/ (accessed on 1 March 2021).

27. O'Brien, A. End-to-end Simulator Technical Memo. CYGNSS Project Doc 148-0123. Available online: https://clasp-research. engin.umich.edu/missions/cygnss/reference/148-0123_CYGNSS_E2ES_EM.pdf (accessed on 1 March 2021).

28. Yang, D.S.; Juang, J.C.; Lin, C.T.; Tsai, Y.F. Verification of GNSS-R Signals for the Triton Mission Payload. In Proceedings of the ICGPSRO 2020, Hsinchu, Taiwan, 21-23 October 2020.

29. Tsai, Y.F.; Hsieh, M.Y.; Chang, H.Y.; Lin, C.T. Development and Test of a Space Capable Miniaturized GPS/GNSS Receiver for Space Applications. In Proceedings of the ION ITM/PTTI 2018, Reston, Virginia, 29 January-1 February 2018. 